\title{
Zika Virus Infection: An Ongoing Global Ferocity
}

\author{
Received: November 2, 2016 Accepted: November 29, 2016 \\ doi: http://dx.doi.org/10.3329/jemc.v7i1.30743
}

Zika virus is an arthropod-borne flavivirus transmitted by female Aedes aegypti mosquito which lives in tropical regions. However, the Aedes albopictus mosquito, which lives in temperate regions, is also capable of carrying it. Like other flaviviruses, Zika virus is enveloped and icosahedral. It has a nonsegmented, single-stranded and 10 kilobase positive-sense RNA genome. The envelope also contains two glycoproteins $\mathrm{E}$ and $\mathrm{M}$; here the E protein binds with the host cell membrane followed by endocytic uptake, uncoating of the nucleocapsid and release of viral RNA into the cytoplasm. Immature virions are collected both in the endoplasmic reticulum and in secretory vesicles before being released. ${ }^{1}$ Flaviviruses generally replicate in the cytoplasm, but Zika virus antigens have been found in infected cell nuclei. The vertebrate hosts of the virus are primarily monkey and human. The pathogenesis of the virus is hypothesized to start with an infection of dendritic cells near the site of mosquito-bite, followed by spreads to the lymph nodes and also the blood stream.

Zika virus is named after the Zika forest in Uganda where it was first isolated from a rhesus monkey in 1947. The first human cases were detected in 1952 in Uganda and Tanzania. ${ }^{2}$ The virus subsequently spreads across the equatorial Africa and Asia. The first major recognized outbreak occurred in 2007 in the Yap Islands of Micronesia where more than 70 percent of the infected individuals were children. ${ }^{3}$ Another larger outbreak affected nearly two-thirds of the population in French Polynesia during 2013 to $2014{ }^{4}$ Subsequently, Zika virus infections were detected in the Western hemisphere on Chile's Easter Island and in Brazil in February 2014 and in May 2015 respectively. ${ }^{5}$ Recently, reports of Zika virus outbreak were obtained from Americas, Africa, the Caribbean, South East Asia and the Pacific Islands. The World Health Organization (WHO) has declared Zika virus infection a Public Health Emergency of International Concern for its explosive nature of spreading. Zika cases in Singapore have shown a dramatic rise in the current year. ${ }^{6} \mathrm{~A}$ report from New York city regarding travel-associated exposure to Zika virus has shown 182 positive cases
(5\%) that included 20 pregnant women also, while 3605 Zika suspected individuals underwent laboratory testing during January to June 2016 . $^{7}$ The first case of Zikarelated congenital microcephaly in the United States was reported in January 2016 in Hawaii, born to a woman who resided in Brazil during pregnancy. ${ }^{8}$ Moreover, in February 2016, the first case of sexually transmitted Zika virus infection in the United States was reported in Texas. ${ }^{9}$

Bangladesh reported its first case of the Zika virus in an old specimen of blood from a 67-year-old man living in Chittagong Port City, who had not been overseas. ${ }^{10}$ Although actual scenario of Zika virus consequences in our country is not adequately documented, few sporadic cases of microcephaly are often found. Those cases still remained unscreened and unreported also. However, the Director of Institute of Epidemiology, Disease Control and Research (IEDCR) has assured about adequate surveillance and screening arrangements for Zika virus infection.

Zika virus may be transmitted to human via different routes, e.g., bite of an infected mosquito, transplacental transmission, sexual contact, transfusion of blood products and organ transplantation. The incubation period between mosquito bite and onset of clinical manifestations is typically 3 to 12 days. The clinical features in adults typically include acute onset of lowgrade fever, maculopapular pruritic rash, arthralgia (notably the small joints of hands and feet), and conjunctivitis (nonpurulent). ${ }^{11}$ Other commonly reported clinical manifestations include myalgia, headache, retro-orbital pain, and asthenia. Zika virus infection may be complicated with congenital microcephaly and fetal losses among women infected during pregnancy. There have been several descriptions of Guillain-Barré syndrome (GBS) in association with Zika virus infection though exact reason is yet to be known. ${ }^{12}$

Zika virus infection should be suspected when typical clinical manifestations and relevant epidemiologic exposure are found. Though it is challenging, the laboratory diagnosis of Zika virus infection can be 
confirmed either by detection of viral RNA or antigen in serum or other body fluids within 1 to 3 days or by detection of IgM antibody specific for Zika virus and Zika virus plaque-reduction neutralization test (PRNT) 3 to 5 days after appearance of symptoms. ${ }^{13}$ Though PRNT is unique to determine the infectivity, a positive IgM antibody result against Zika virus reflects recent infection. The FDA has approved Emergency Use Authorization (EUA) of several diagnostic tools for Zika virus, including the Trioplex Real-Time RT-PCR (rRT-PCR) assay and the Zika MAC-ELISA. ${ }^{14}$

There is no specific treatment for Zika virus infection. Management consists of rest and symptomatic treatment, including drinking plenty of fluids to prevent dehydration and administration of acetaminophen to relieve fever and pain. Aspirin and other nonsteroidal anti-inflammatory drugs (NSAIDS) should be avoided until dengue infection has been ruled out to reduce the risk of hemorrhage.

So far no vaccine has been developed for prevention of Zika virus infection. In June 2016, the FDA primarily approved for a human clinical trial of Zika vaccine. ${ }^{15}$ Current preventive strategies focus on mosquito control, protection against mosquito-bite (e.g., use of mosquito curtain, insect repellent, long-sleeved clothing) and screening of blood specimens in Zika infected areas. These and other measures should gain momentum as Zika has been declared an emergency. Since an effective vaccine or proper treatment is still a long way off, intensive research on Zika virus with enhanced surveillance by convening experts and partners need to be initiated in order to minimize the ongoing crisis created by Zika virus. Until a vaccine is available, keeping surroundings clean, increasing public awareness and taking appropriate control measures are among the best alternatives to combat aggressiveness of Zika virus.

\section{Iftikhar Ahmed}

Professor, Department of Microbiology

Enam Medical College, Savar, Dhaka

Email: ia65831@gmail.com

\section{References}

1. Sirohi D, Chen Z, Sun L, Klose T, Pierson TC, Rossmann MG et al. The $3.8 \AA$ resolution cryo-EM structure of Zika virus. Science 2016; 22; 352(6284): 467-470.
2. World Health Organization. Emergencies: the history of Zika virus. Available at: http://www.who.int/emergencies/zikavirus/timeline/en/. Accessed February 2016.

3. Duffy MR, Chen TH, Hancock WT, Powers AM, Kool JL, Lanciottii RS et al. Zika virus outbreak on Yap Island, Federated States of Micronesia. N Engl J Med 2009; 360: 2536-2543.

4. Cauchemez S, Besnard M, Bompard P, Dub T, GuillemetteArtur P, Eyrolle-Guignot D et al. Association between Zika virus and microcephaly in French Polynesia, 2013-15: a retrospective study. Lancet 2016; 387: 2125-2132.

5. Chen LH, Hamer DH. Zika virus: rapid spread in the Western Hemisphere. Ann Intern Med 2016; 164: 613-615.

6. World Health Organization. WHO Director-General briefs Executive Board on Zika situation. Available at: http://www.who.int/dg/speeches/2016/zika-situation/en/. Accessed January 2016.

7. Fauci AS, Morens DM. Zika virus in the Americas-yet another Arbovirus threat. N Engl J Med 2016; 374: 601-604.

8. State of Hawaii. DOH news release: Hawaii Department of Health receives confirmation of Zika infection in baby born with microcephaly. Available at: http://governor.hawaii.gov/ newsroom/doh-news-release-hawaii-department-of-healthreceives-confirmation-of-zika-infection-in-baby-born-withmicrocephaly/. Accessed January 2016.

9. Dallas County Health and Human Services. DCHHS reports first Zika virus case in Dallas county acquired through sexual transmission. Available at: http://www.dallascounty. org/department/hhs/press/documents/PR2-2-16DCHHS ReportsFirstCaseofZikaVirusThroughSexualTransmission. pdf. Accessed February 2016.

10. Bangladeshis infected with Zika in Singapore. Available at: http://www.thedailystar.com. Accessed September 2016.

11. Chen LH. Zika virus infection in a Massachusetts resident after travel to Costa Rica: a case report. Ann Intern Med 2016; 164(8): 574-576.

12. Dos Santos T, Rodriguez A, Almiron M, Sanhueza A, Ramon $\mathrm{P}$, de Oliveira WK et al. Zika virus and the Guillain-Barre syndrome - case series from seven countries. N Engl J Med 2016; 375(16): 1598-1601.

13. Centers for Disease Control and Prevention. CDC Health Alert Network (HAN) health update: CDC recommendations for subsequent Zika IgM antibody testing. Available at: https://content.govdelivery.com/accounts/USCDC/ bulletins/150b812. Accessed June 2016.

14. Rabe IB, Staples JE, Villanueva J, Hummel KB, Johnson JA, Rose $\mathrm{L}$ et al. Interim guidance for interpretation of Zika virus antibody test results. Morb Mortal Wkly Rep 2016; 65(21): 543-546.

15. Experimental Zika vaccine is approved for clinical trials for first time in USA. Available at: https://www.statnews.com// zika-vaccine-inovio/. Accessed June 2016. 